\title{
An Examination of Lactobacillus paracasei GKS6 and Bifidobacterium lactis GKK2 Isolated from Infant Feces in an Aged Mouse Model
}

\author{
Shih-Wei Lin $\mathbb{D}^{1},{ }^{1}$ You-Shan Tsai $\mathbb{D}^{2},{ }^{2}$ Yen-Lien Chen $\mathbb{D}^{2},{ }^{2}$ Ming-Fu Wang $\mathbb{D}{ }^{3}$ \\ Chin-Chu Chen $\left(\mathbb{1},{ }^{4,5,6}\right.$ Wen-Hsin Lin $\left(\mathbb{1},{ }^{7}\right.$ and Tony J. Fang $\mathbb{1}^{1}$ \\ ${ }^{1}$ Department of Food Science and Biotechnology, National Chung Hsing University, Taichung 402204, Taiwan \\ ${ }^{2}$ Biotech Research Institute, Grape King Bio Ltd., Taoyuan 325002, Taiwan \\ ${ }^{3}$ Department of Food and Nutrition, Providence University, Taichung 433303, Taiwan \\ ${ }^{4}$ Institute of Food Science and Technology, National Taiwan University, Taipei 106319, Taiwan \\ ${ }^{5}$ Department of Food Science, Nutrition and Nutraceutical Biotechnology, Shih Chien University, Taipei 104336, Taiwan \\ ${ }^{6}$ Department of Bioscience Technology, Chung Yuan Christian University, Taoyuan 320314, Taiwan \\ ${ }^{7}$ Department of Pharmacy, China Medical University, Taichung 404333, Taiwan
}

Correspondence should be addressed to Wen-Hsin Lin; wslin@mail.cmu.edu.tw and Tony J. Fang; tjfang@nchu.edu.tw

Received 29 December 2020; Revised 1 March 2021; Accepted 10 March 2021; Published 9 April 2021

Academic Editor: Riaz Ullah

Copyright ( 2021 Shih-Wei Lin et al. This is an open access article distributed under the Creative Commons Attribution License, which permits unrestricted use, distribution, and reproduction in any medium, provided the original work is properly cited.

Supplementary which could maintain normal physiological mechanisms and functions while aging has drawn our attention due to the population aging in recent years. Probiotics have been believed with desirable properties such as antioxidation and antiinflammatory for delaying the aging process. However, the age-related experiments conducted in the mammalian models with probiotics were few. In this study, we demonstrated the effects of administration of probiotics Lactobacillus paracasei GKS6 (GKS6) and Bifidobacterium lactis GKK2 (GKK2), respectively, at the dosage of $5.0 \times 10^{9} \mathrm{cfu} / \mathrm{kg} \mathrm{BW} /$ day for fourteen weeks in senescence-accelerated mouse prone 8 (SAMP8) mice. The three-month-old SAMP8 mice were divided into three groups: control, mice fed with GKS6, and mice fed with GKK2. There were ten females and ten males in each group. The SAMP8 mice fed with probiotics GKS6 and GKK2 showed a significantly lower degree of aging followed by Takeda's grading method on the eleventh week of the experiment. The GKK2 group showed significantly increased forelimb grip strength in male SAMP8 mice and muscle fiber number in both genders. Compared to the control, both GKS6 and GKK2 presented a significant increase in liver superoxide dismutase and catalase activities. In addition, a significant decrease in the levels of liver thiobarbituric acid-reactive substances was observed in the probiotics group. These results suggested that probiotics GKS6 and GKK2 could act as antioxidants in delaying the process of aging and preventing age-related muscle loss.

\section{Introduction}

The number and proportion of people aged sixty years and older in the population are increasing [1]. According to the report from the World Health Organization (WHO), the number of elderly ( $>60$ years old) was calculated as one billion in 2019 and was expected to be two billion by 2050. As aging increases, the normal functions of various organs or tissues in the body gradually decline, leading to a decrease in mobility, antioxidant defense system, and immunity [2-4].
In addition, the reduction of antioxidant substances in the body would easily develop relative diseases such as immune disorder, cardiovascular diseases, and frailty syndrome [5-7]. Therefore, it is attracting attention on maintaining normal physiological mechanisms and functions during the aging process [8].

One of the age-related figures was muscle loss, including the loss of muscle mass and the loss of muscle function which could be developing to sarcopenia or dynapenia [9-11]. It has been reported that over 30\% prevalence in 
those aged eighty years and older suffered sarcopenia [12]. Although the reason for age-related muscle decline has not been clear yet, some scientists suggested that oxidative stress, reactive oxygen species (ROS), for example, could affect cell signaling pathways, promote proteolysis, and inhibit protein synthesis in muscle fibers [13, 14]. Another explanation resulted from inflammatory cytokines IL- 6 and TNF- $\alpha$, for example, the introduction of inflammatory markers that could cause muscle breakdown, was being conducted $[15,16]$.

Probiotics have been reported with effects on antioxidation, anti-inflammatory, and metabolic regulation [17-19]. Although these properties were highly linked to delay the aging process, there have been few reported about antiaging in mammalian models. In our previous studies, we isolated two bacteria strains, Lactobacillus paracasei GKS6 (GKS6) and Bifidobacterium lactis GKK2 (GKK2), from healthy infant feces. Both strains presented potential properties with application as probiotics in acid and bile tolerance tests. Probiotics L. paracasei GKS6 had been reported with metabolic modulation in alcohol diet mouse model and antiosteoporosis in ovariectomized mice [20,21]. B. lactis GKK2 showed immune enhancement in the OVAinduced murine model [22]. These evidences provided the possibility of contributing to delaying the development of aging and raised our interest [23].

The senescence-accelerated mouse prone 8 (SAMP8) is widely used in age-related studies [24]. It is a spontaneous age-accelerated mouse model of AKR/J inbred line bred by Pf. Takeda (Kyoto University, Japan) in the early 1980s [25]. The figure of SAMP8 includes comparatively old appearance, fast decline of organ function, and short life span. For the evaluation of probiotics GKS6 and GKK2 on delaying aging, SAMP8 was introduced in this study. After fourteen weeks of administration of GKS6 and GKK2, the age-associated parameters in SAMP8 were measured.

\section{Materials and Methods}

2.1. Bacteria Preparation. Both Lactobacillus paracasei GKS6 (BCRC 910788) and Bifidobacterium lactis GKK2 (BCRC 910826) were isolated from healthy Taiwanese infant feces. The bacteria strains were, respectively, cultured at $37^{\circ} \mathrm{C}$ and $\mathrm{pH} 6.0$ under anaerobic conditions for $16 \mathrm{~h}$ with the following medium: $5 \%$ glucose, $2 \%$ yeast extract, $0.05 \% \mathrm{MgSO}_{4}$, $0.1 \% \mathrm{~K}_{2} \mathrm{HPO}_{4}$, and $0.1 \%$ Tween-80. For harvesting, the fermented bacteria were centrifuged and mixed with protectant and then freeze-dried at $25^{\circ} \mathrm{C}$ for 48 hours. The live bacteria were counted by plate counting.

2.2. Animal Subjects. The three-month-old senescenceaccelerated mice prone P8 (SAMP8) were housed under $25 \pm 2{ }^{\circ} \mathrm{C}, 65 \pm 5 \% \mathrm{RH}$ at $12 \mathrm{~h}$ dark/light cycle with food and water ad libitum. A total of sixty SAMP8 mice were divided into three groups ( $n=10$ in each gender): control (saline), mice fed with probiotics GKS6, and mice fed with probiotics GKK2. The probiotics were continuously given for fourteen weeks with a dosage of $5.0 \times 10^{9} \mathrm{cfu} / \mathrm{kg}$ BW/day. The animal protocol in this study has been approved by the Institutional Animal Care and Use Committee (IACUC no. 20170629A02).

2.3. Grading Score of Senescence. On the eleventh week of the experiment, the degree of senescence on SAMP8 was evaluated by Takeda's method [25]. The evaluation was included as follows: (1) behavior of reactivity, (2) behavior of passivity, (3) glossiness, (4) coarseness, (5) hair loss, (6) skin ulcer, (7) eye periophthalmic lesions, and (8) spine lordokyphosis. There were five grades from score 0 to score 4 representing the degree of senescence from slight to serve in each category. The total score was summed.

2.4. Grip Strength Test. The forelimb grip strength of SAMP8 mice was tested on the twelfth week by Grip Strength Meter (GSM 47200, Ugo Basile S.R.L., VA, Italy). The maximal force was recorded.

2.5. Biochemical Analysis. On the fourth week of the experiment, the SAMP8 mice blood was collected from the orbital sinus and centrifuged at $6000 \mathrm{rpm}$ and at $4^{\circ} \mathrm{C}$ for 5 minutes and then stored at $-20^{\circ} \mathrm{C}$. The following parameters were analyzed by Beckman D $\times$ C 800 chemistry analyzer (Beckman Coulter, CA, USA): glucose, total protein, albumin, triglycerides, total cholesterol, high-density/low-density lipoprotein cholesterol (HDL-C/LDL-C), glutamate oxaloacetate transaminase (GOT), glutamic pyruvic transaminase (GPT), blood urea nitrogen (BUN), and creatinine.

2.6. Determination of Oxidative Parameters. $25 \mathrm{mg}$ liver tissue was homogenized with $250 \mu \mathrm{l}$ RIPA buffer and then centrifuged at $1600 \times \mathrm{g}$ and $4^{\circ} \mathrm{C}$ for 10 minutes. The supernatant was collected and stored at $-80^{\circ} \mathrm{C}$ for use. The superoxide dismutase (SOD) activity in the liver was analyzed by Randox assay kit (Cat. no. SD125, Randox Laboratories, ANT, UK) with absorbance at $340 \mathrm{~nm}$. The catalase assay kit (Cat. no. 707002, Cayman Chemical, MI, USA) was used with $540 \mathrm{~nm}$ adsorption rate for the detection of catalase activity in the liver. For analyzing the levels of thiobarbituric acid reactive substances (TBARS) in mouse liver, $100 \mu \mathrm{l}$ homogenized liver supernatant was mixed with $100 \mu \mathrm{l}$ sodium dodecyl sulfate (SDS) solution and $4 \mathrm{ml}$ color reagent under boiled water for an hour and then ice-cooled. The mixture was centrifuged at $1600 \times g$ under $4^{\circ} \mathrm{C}$ for 10 minutes and then the absorbance value was read at $535 \mathrm{~nm}$ spectrophotometrically. The data were expressed as equivalent malondialdehyde (MDA) $\mu \mathrm{M} / \mathrm{g}$ protein [26].

2.7. Immunohistochemical Analysis of Muscle Cells. After sacrifice, mouse muscle tissue was washed with $0.9 \%$ saline and fixed in $10 \%$ formalin. Tissues were embedded in paraffin and cut into $4 \mu \mathrm{m}$ thick slices for morphological and pathological evaluations. Immunohistochemical (IHC) staining of tissues involved the use of the Leica antibody to myosin heavy chain fast (WB-MHCf) and myosin heavy 
chain slow (WB-MHCs). By using automated BondMax with double staining, WB-MHCf and WB-MHCs epitope retrieval involved the use of ER2 (AR9640) retrieval solution for $30 \mathrm{~min}$ once, followed by incubation with WB-MHCf and WB-MHCs antibodies with diluent 100X for $30 \mathrm{~min}$. The detection kit used was the Bond Polymer Refine Detection (DS9800) (incubation with post-primary for $8 \mathrm{~min}$, polymer for $8 \mathrm{~min}$, and $3^{\prime} 3^{\prime}$-diaminobenzidine for $5 \mathrm{~min}$ ) and Bond Polymer Refine Red Detection (DS9390) (incubation with post-primary for $20 \mathrm{~min}$, polymer for $30 \mathrm{~min}$, red for $10 \mathrm{~min}$, and haematoxylin for $5 \mathrm{~min}$ ). Finally, results were examined under a light microscope equipped with a CCD camera (BX-51, Olympus, Tokyo) by a veterinary pathologist.

2.8. Statistical Analysis. Data are presented as mean \pm SEM ( $n=10$ in each gender) and analyzed by one-way ANOVA with SPSS 19.0 (SPSS, NY, USA). For the comparison of statistical significance among the groups, Duncan's multiple range test was used. A $p$ value $<0.05$ was considered statistically significant.

\section{Results}

3.1. Body Weight and General Characteristics of SAMP8 Mice with or without Probiotics. There was no significant difference at the first week of all SAMP8 mice after grouping. The food intake and water consumption during the experiment were not significantly different (data not shown). Figure 1 shows the weight changes during fourteen weeks of probiotics consumption. Male SAMP8 mice gained about two to three grams of weight on average at the end of the experiment with no significant difference among the groups (Figure 1(a)). There was also no significant difference in weight changes among the treatments in the female gender (Figure 1(b)). The relative organ weights were presented as normal in both genders when compared with the control group (Table 1). In addition, probiotics GKS6 and GKK2 did not affect biochemical parameters.

\subsection{Effect of Probiotics L. paracasei GKS6 and B. lactis GKK2} on the Score of Senescence. The degree of senescence in threemonth-old SAMP8 mice was scored on the eleventh week of the experiment. The characteristics of SAMP8 mice showed an aging appearance including dull or rough hair, hair loss, turbid eyes, and lordokyphosis. Both control male and female SAMP8 mice presented a severe senescence appearance with total grading scores at $3.0 \pm 0.33$ and $4.9 \pm 0.23$, respectively (Figure 2). Probiotics GKS6 significantly reduced the degree of senescence in skin, eyes, and spine, which presented a total aging score at $1.0 \pm 0.33$ in both genders. With supplementary use of probiotics GKK2, the SAMP8 male and female mice also showed a significantly lower senescence $(p<0.05)$. These results suggested that administration of probiotics GKS6 and GKK2 provided effects on delaying the process of aging.
3.3. Effect of Probiotics L. paracasei GKS6 and B. lactis GKK2 on Grip Strength. In the grip strength test, control male mice presented a better grip strength than control female mice. Both probiotics GKS6 and GKK2 had no effect on the maximal peak force developed by female SAMP8 mice in a comparison with the female control (Figure 3). Administration of L. paracasei GKS6 showed a tendency of increased strength in male SAMP8 when compared to the male control, although it has not reached statistical significance. The male SAMP8 mice fed with B. lactis GKK2 presented significantly greater grip strength than the control male mice $(p<0.05)$. It is demonstrated that both probiotics GKS6 and GKK2 supplementation could alleviate the strength loss caused by aging in the male animal model.

3.4. Effect of Probiotics GKS6 and GKK2 on SAMP8 Mouse Muscle Cells. Histological results revealed that there was no clear difference in fiber arrangement among the SAMP8 mice, as well as the proportion of type I and type II fibers (Figure 4(a)). Both GKS6 and GKK2 did not affect the fiber size in SAMP8 mice, regardless of gender. The probiotics GKS6 showed a tendency of increase in muscle cell count of male SAMP8 (Figure 4(b)). A significant increase in muscle fiber was observed in the GKK2 group when, respectively, compared to the control male and female group $(p<0.05)$. It is suggested that probiotics GKK2 could contribute to alleviating the loss of muscle fibers associated with muscle aging.

3.5. Effect of Probiotics GKS6 and GKK2 on Oxidative Parameters in SAMP8 Mouse. SOD and catalase are enzymes that involve in reactive oxygen species (ROS) scavenging. The activity of liver SOD in SAMP8 mice was significantly greater with probiotics GKS6 and GKK2, respectively, than with the control (Figure 5(a)). Similar results were observed with catalase activity in the SAMP8 mouse liver, as shown in Figure 5(b). It is indicated that both administration of GKS6 and GKK2 could improve the antioxidants activity in an aged mouse model. In addition, MDA reacted to TBARS were less detected in the liver tissue of GKS6 and GKK2 groups with $p<0.05$ (Figure 5(c)). Furthermore, the TBARS and 8 -hydoxy-2-deoxyguanosine $(8-\mathrm{OHdG})$ in mouse brain were also detected with lower level in both probiotics groups when compared to the control (Figure S1). The effect of probiotics GKS6 and GKK2 on lipid oxidation during the aging process was revealed.

\section{Discussion}

In the present study, administration of probiotics GKS6 and GKK2 demonstrated a delayed effect on aging. However, the mechanisms of these two strains were supposed to be different based on our previous experiments and partial unrevealed data. There was a possibility that the effect of B. lactis GKK2 on antiaging was contributed by mitochondrial antioxidation; whereas the effect of $L$. paracasei GKS6 could be explained by the anti-inflammatory. 


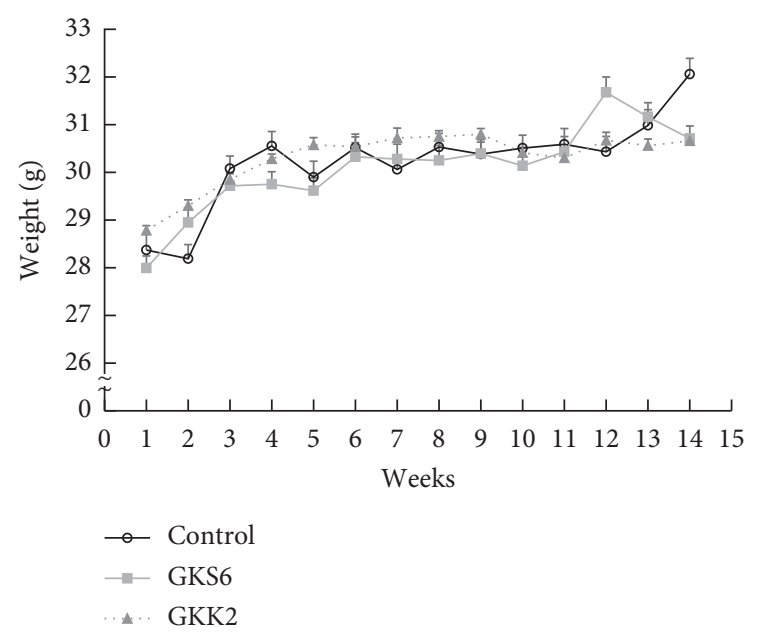

(a)

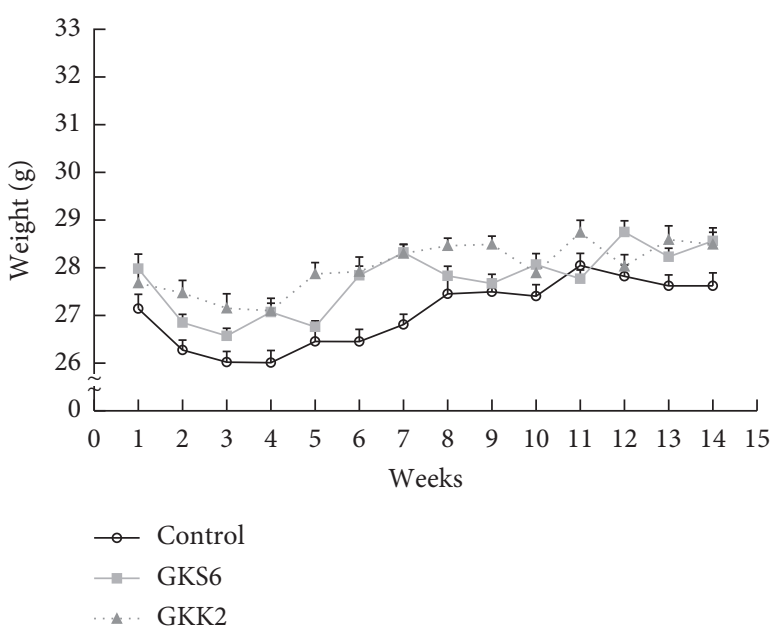

(b)

FIGURE 1: Weight changes of SAMP8 mice during the experiment. The SAMP8 male (a) and female (b) mice weights during fourteen weeks were presented as means \pm SEM and analyzed by one-way ANOVA $(n=10)$. The probiotics were given at a dosage of $5.0 \times 10^{9} \mathrm{CFU} / \mathrm{kg} \mathrm{BW} /$ day. Control: SAMP8 mice fed with saline; GKS6: SAMP8 mice fed with L. paracasei GKS6; GKK2: SAMP8 mice fed with B. lactis GKK2.

TABLE 1: Relative organ weights and plasma biochemical parameters of SAMP8 mice.

\begin{tabular}{|c|c|c|c|c|c|c|}
\hline \multirow[b]{2}{*}{ Group } & \multicolumn{3}{|c|}{ Male } & \multicolumn{3}{|c|}{ Female } \\
\hline & Control & GKS6 & GKK2 & Control & GKS6 & GKK2 \\
\hline \multicolumn{7}{|c|}{ Relative weight (g/100 g body weight) } \\
\hline Brain & $1.440 \pm 0.038^{\mathrm{a}}$ & $1.535 \pm 0.012^{\mathrm{a}}$ & $1.524 \pm 0.017^{\mathrm{a}}$ & $1.736 \pm 0.043^{\mathrm{a}}$ & $1.782 \pm 0.049^{\mathrm{a}}$ & $1.769 \pm 0.061^{\mathrm{a}}$ \\
\hline Heart & $0.662 \pm 0.025^{\mathrm{a}}$ & $0.651 \pm 0.023^{\mathrm{a}}$ & $0.673 \pm 0.018^{\mathrm{a}}$ & $0.564 \pm 0.017^{\mathrm{a}}$ & $0.597 \pm 0.025^{\mathrm{a}}$ & $0.556 \pm 0.026^{\mathrm{a}}$ \\
\hline Liver & $4.853 \pm 0.282^{\mathrm{a}}$ & $4.829 \pm 0.235^{\mathrm{a}}$ & $4.369 \pm 0.174^{\mathrm{a}}$ & $4.651 \pm 0.201^{\mathrm{a}}$ & $4.442 \pm 0.115^{\mathrm{a}}$ & $4.768 \pm 0.288^{\mathrm{a}}$ \\
\hline Spleen & $0.352 \pm 0.037^{\mathrm{a}}$ & $0.294 \pm 0.015^{\mathrm{a}}$ & $0.264 \pm 0.018^{\mathrm{a}}$ & $0.431 \pm 0.037^{\mathrm{a}}$ & $0.444 \pm 0.023^{\mathrm{a}}$ & $0.458 \pm 0.033^{\mathrm{a}}$ \\
\hline Lung & $0.720 \pm 0.030^{\mathrm{a}}$ & $0.805 \pm 0.033^{\mathrm{a}}$ & $0.798 \pm 0.045^{\mathrm{a}}$ & $0.836 \pm 0.045^{\mathrm{a}}$ & $0.772 \pm 0.020^{\mathrm{a}}$ & $0.860 \pm 0.033^{\mathrm{a}}$ \\
\hline Kidney & $1.710 \pm 0.064^{\mathrm{a}}$ & $1.713 \pm 0.046^{\mathrm{a}}$ & $1.663 \pm 0.074^{\mathrm{a}}$ & $1.264 \pm 0.020^{\mathrm{a}}$ & $1.264 \pm 0.021^{\mathrm{a}}$ & $1.273 \pm 0.044^{\mathrm{a}}$ \\
\hline \multicolumn{7}{|c|}{ Plasma biochemical parameters } \\
\hline Albumin (g/d) & $2.92 \pm 0.09^{\mathrm{a}}$ & $3.11 \pm 0.07^{\mathrm{a}}$ & $3.14 \pm 0.06^{\mathrm{a}}$ & $3.45 \pm 0.07^{\mathrm{a}}$ & $3.50 \pm 0.09^{\mathrm{a}}$ & $3.50 \pm 0.11^{\mathrm{a}}$ \\
\hline Glucose (mg/dl) & $154.5 \pm 5.47^{\mathrm{a}}$ & $159.90 \pm 4.14^{\mathrm{a}}$ & $159.10 \pm 5.34^{\mathrm{a}}$ & $162.60 \pm 5.66^{\mathrm{a}}$ & $155.30 \pm 5.81^{\mathrm{a}}$ & $161.10 \pm 3.57^{\mathrm{a}}$ \\
\hline Total cholesterol (mg/dl) & $138.10 \pm 6.81^{\mathrm{a}}$ & $145.30 \pm 4.71^{\mathrm{a}}$ & $144.20 \pm 4.58^{\mathrm{a}}$ & $99.50 \pm 2.98^{\mathrm{a}}$ & $100.90 \pm 2.18^{\mathrm{a}}$ & $101.90 \pm 2.61^{\mathrm{a}}$ \\
\hline Triglyceride (mg/dl) & $97.30 \pm 3.36^{\mathrm{a}}$ & $99.30 \pm 3.16^{\mathrm{a}}$ & $101.30 \pm 4.35^{\mathrm{a}}$ & $98.90 \pm 3.05^{\mathrm{a}}$ & $100.60 \pm 4.11^{\mathrm{a}}$ & $99.60 \pm 1.10^{\mathrm{a}}$ \\
\hline HDL (mg/dl) & $109.81 \pm 5.14^{\mathrm{a}}$ & $108.73 \pm 2.71^{\mathrm{a}}$ & $112.84 \pm 4.58^{\mathrm{a}}$ & $61.01 \pm 4.88^{\mathrm{a}}$ & $53.57 \pm 5.70^{\mathrm{a}}$ & $46.25 \pm 6.12^{\mathrm{a}}$ \\
\hline Total protein $(\mathrm{mg} / \mathrm{dl})$ & $5.94 \pm 0.15^{\mathrm{a}}$ & $6.32 \pm 0.22^{\mathrm{a}}$ & $6.44 \pm 0.22^{\mathrm{a}}$ & $6.06 \pm 0.10^{\mathrm{a}}$ & $6.04 \pm 0.07^{\mathrm{a}}$ & $5.89 \pm 0.11^{\mathrm{a}}$ \\
\hline $\mathrm{LDL}(\mathrm{mg} / \mathrm{dl})$ & $18.70 \pm 2.65^{\mathrm{a}}$ & $18.20 \pm 1.73^{\mathrm{a}}$ & $22.10 \pm 1.42^{\mathrm{a}}$ & $9.17 \pm 0.96^{\mathrm{a}}$ & $7.88 \pm 0.10^{\mathrm{a}}$ & $18.87 \pm 5.73^{\mathrm{a}}$ \\
\hline GPT (U/L) & $47.40 \pm 5.53^{\mathrm{a}}$ & $45.80 \pm 3.85^{\mathrm{a}}$ & $46.30 \pm 3.80^{\mathrm{a}}$ & $61.30 \pm 5.36^{\mathrm{a}}$ & $63.70 \pm 5.43^{\mathrm{a}}$ & $64.10 \pm 4.47^{\mathrm{a}}$ \\
\hline GOT $(\mathrm{U} / \mathrm{L})$ & $181.80 \pm 17.01^{\mathrm{a}}$ & $179.20 \pm 9.53^{\mathrm{a}}$ & $173.40 \pm 10.99^{\mathrm{a}}$ & $178.80 \pm 9.40^{\mathrm{a}}$ & $172.70 \pm 11.22^{\mathrm{a}}$ & $177.70 \pm 12.70^{\mathrm{a}}$ \\
\hline BUN (mg/dl) & $27.19 \pm 1.96^{\mathrm{a}}$ & $26.95 \pm 0.73^{\mathrm{a}}$ & $29.27 \pm 2.34^{\mathrm{a}}$ & $25.93 \pm 2.00^{\mathrm{a}}$ & $23.54 \pm 0.72^{\mathrm{a}}$ & $25.78 \pm 2.21^{\mathrm{a}}$ \\
\hline Creatinine $(\mathrm{mg} / \mathrm{dl})$ & $0.31 \pm 0.02^{\mathrm{a}}$ & $0.33 \pm 0.02^{\mathrm{a}}$ & $0.30 \pm 0.22^{\mathrm{a}}$ & $0.32 \pm 0.02^{\mathrm{a}}$ & $0.35 \pm 0.01^{\mathrm{a}}$ & $0.37 \pm 0.02^{\mathrm{a}}$ \\
\hline
\end{tabular}

Values were presented as mean \pm SEM $(n=10)$ (one-way ANOVA). Alphabet "a” represented no significant difference by Duncan's multiple range test. The SAMP8 mice were given saline or probiotics at a dosage of $5.0 \times 10^{9} \mathrm{CFU} / \mathrm{kg}$ BW/day. GKS6:L. paracasei GKS6; GKK2: B. lactis GKK2.

The CDGSH iron-sulfur domain 2 (Cisd2), a redoxsensitive gene, was reported with a crucial role in the lifespan and the development of age-related diseases [27]. In our preliminary test, an enhancement of Cisd2 gene expression in HEK293T cells was presented in GKK2 treatment but not in the GKS6 group (Figure S2). A persistent level of Cisd2 protected mitochondrial dysregulation and reduced DNA damage caused by oxidative stress; in addition, Cisd 2 was involved in calcium homeostasis through the regulation of the calcium channels located on the endoplasmic reticulum and mitochondrial outer membranes [28-30]. These affections maintain a better physical function in skeletal muscle, liver, and heart [31, 32]. The Cisd $2 \mathrm{mKO}$ mice showed a similar pattern as naturally aged mice in the decline of gastrocnemius muscle [33]. It explained that GKK2 increased grip strength and muscle mass in aged-accelerated mouse models involved with the regulation of the cisd2 gene.

Although GKS6 got lower aging scores than GKK2 in the grading system (Figure 2), it seems like age-dependent muscular parameters were not affected a lot by GKS6 than GKK2. Therefore, it gave us clues that probiotics affect differently on antiaging from strain to strain. We also investigated the ratio of bone volume/tissue volume (BV/TV), trabecular thickness (Tb. Th), trabecular number (Tb. N), 


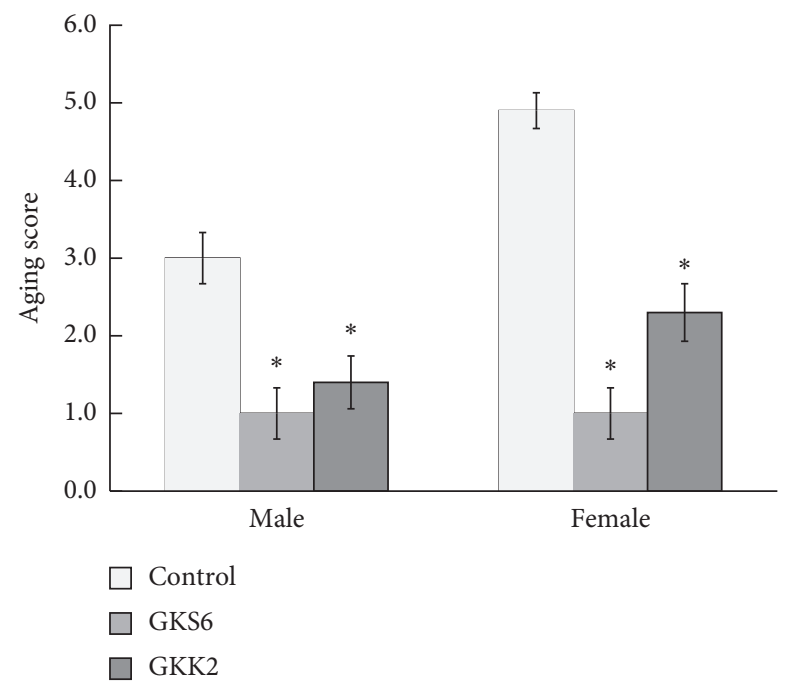

FIGURE 2: Aging score of three-month-old SAMP8 mice on the 11th week. Data were expressed as means \pm SEM and analyzed by one-way ANOVA $(n=10)$. A $p$ value $<0.05$ was regarded as a significant difference with $*$ symbol in the figure. The SAMP8 mice were given saline or probiotics at a dosage of $5.0 \times 10^{9} \mathrm{CFU} / \mathrm{kg}$ BW/day. Control: SAMP8 mice fed with saline; GKS6: SAMP8 mice fed with L. paracasei GKS6; GKK2: SAMP8 mice fed with $B$. lactis GKK2.

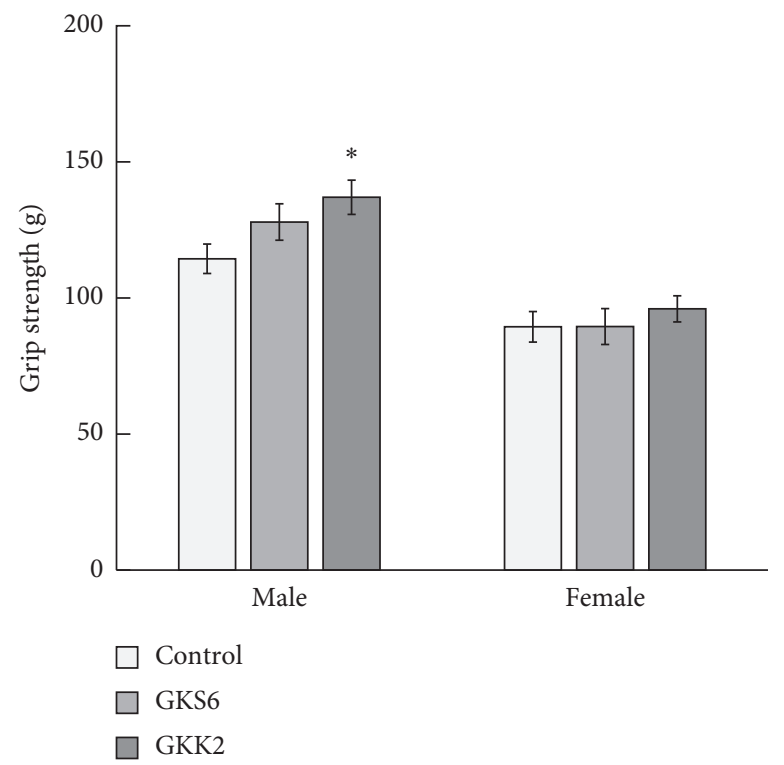

FIGURE 3: Grip strength analysis of three-month-old SAMP8 mice on the 12th week. Data were expressed as means \pm SEM and analyzed by one-way ANOVA $(n=10)$. A $p$ value $<0.05$ was regarded as a significant difference with $*$ symbol in the figure. The SAMP8 mice were given saline or probiotics at a dosage of $5.0 \times 10^{9} \mathrm{CFU} / \mathrm{kg}$ BW/day. Control: SAMP8 mice fed with saline; GKS6: SAMP8 mice fed with $L$. paracasei GKS6; GKK2: SAMP8 mice fed with B. lactis GKK2.

trabecular separation (Tb. $\mathrm{Sp}$ ), and bone mineral density (BMD) in female SAMP8 mice fed with GKS6 (Table S1). Even though the results did not reach statistical significance, the trends in the decrease of Tb. Sp and increase of BMD were similar to our previous study in an ovariectomized mice model [21]. Interestingly, GKS6 relatively maintained higher BV/TV (\%) and Tb. N (No./mm) in SAMP8 females which was not observed in the past. Generally, bone loss due to aging is regarded as a chronic inflammatory state involving increased proinflammatory cytokines such as IL-6, IL-1, and receptor activator of nuclear factor- $\kappa \mathrm{B}$ ligand
(RANKL) $[34,35]$. According to the inhibited effect of GKS6 with RANKL treatment on RANK, the functions of GKS6 in this study on age-related bone loss via anti-inflammatory pathway could be surmised [21].

It could be expected that the combination of GKS6 and GKK2 has a potential synergistic effect on improving agerelated symptoms since they might work differently in physiological function. Fu et al. revealed a similar outcome of antiaging effect with oral Lactobacillus spp. and Bifidobacterium spp., respectively, in C57BL/6 mice; however, the compositions of gut microbiota in mice were very different 


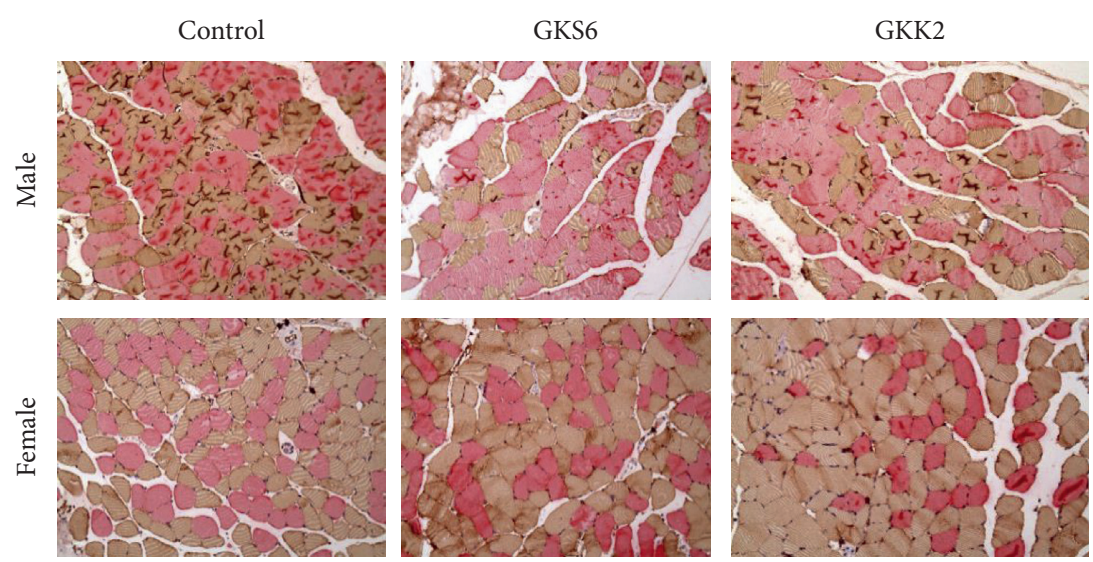

(a)

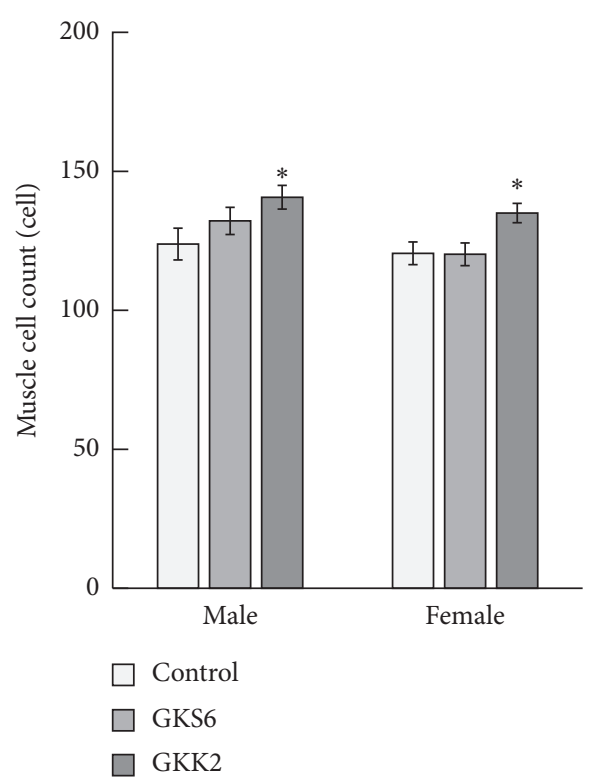

(b)

FIGURE 4: Immunohistochemical identification of muscle cell count at 200x. The muscle tissue of SAMP8 was observed by immunohistochemistry (a) and the cell count was examined (b). Type I fibers and type II fibers were stained as red and orange, respectively. The values of muscle cell count were shown as means \pm S.E.M with one-way ANOVA $(n=10)$. * Significant difference was presented when $p<0.05$. Control: SAMP8 mice fed with saline; GKS6: SAMP8 mice fed with L. paracasei GKS6; GKK2: SAMP8 mice fed with B. lactis GKK2.
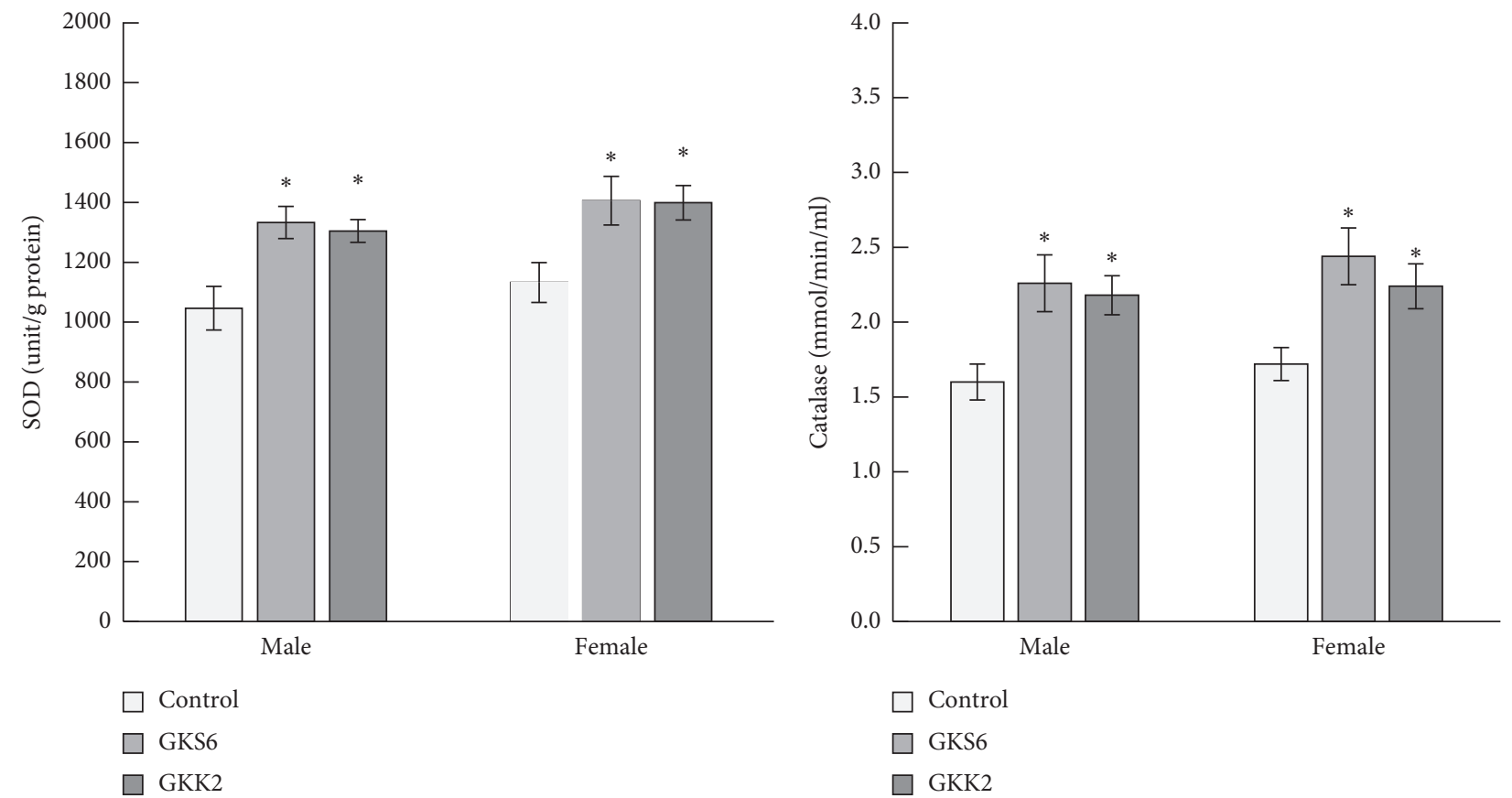

(a)

(b)

Figure 5: Continued. 


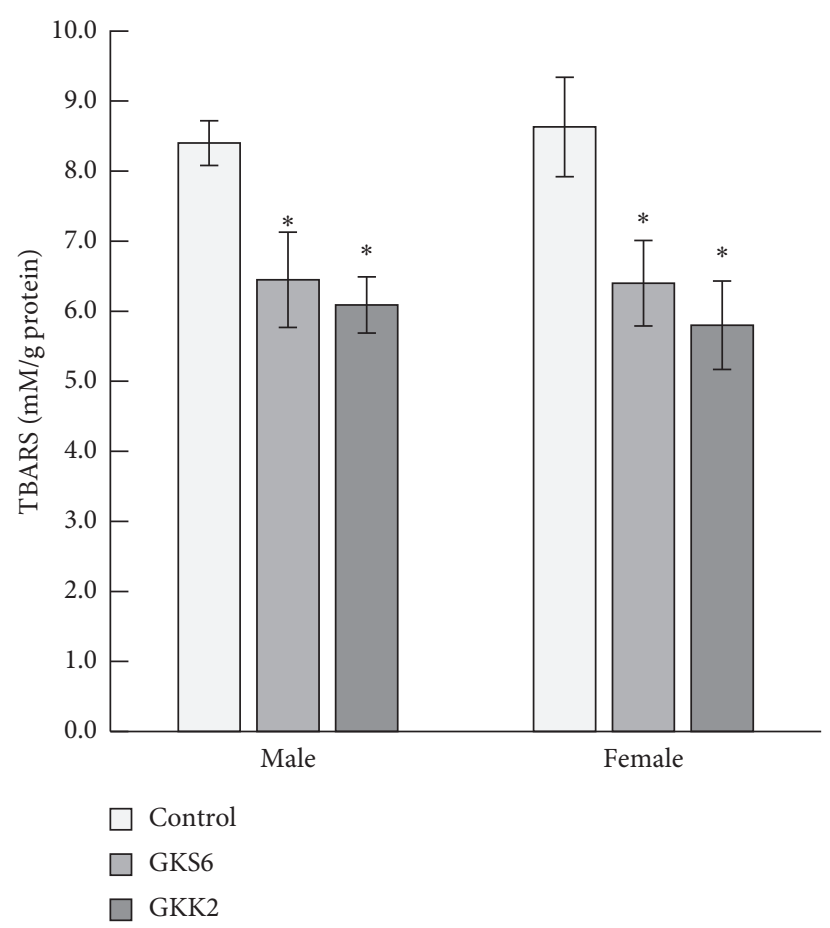

(c)

FIgURE 5: Oxidative stress parameters in the SAMP8 mouse liver. The activities of superoxide dismutase (a), catalase (b), and the concentration of thiobarbituric acid reactive substances (c) in the SAMP8 mouse liver were measured. The values were shown as means \pm SEM with one-way ANOVA $(n=10)$. ${ }^{*}$ Significant difference was presented when $p<0.05$. Control: SAMP8 mice fed with saline; GKS6: SAMP8 mice fed with $L$. paracasei GKS6; GKK2: SAMP8 mice fed with B. lactis GKK2.

between these two treatments [36]. The different role of probiotics on antiaging could provide the complexity of physiological modulation which builds a multiple defense system, that is, providing more appropriate solutions and less bad effect concern. In this study, we contributed to provide two different probiotic strains with different mechanisms for antiaging effect.

\section{Conclusions}

In this study, we demonstrated that dietary supplementation of $L$. paracasei GKS6 and B. lactis GKK2 in SAMP8 mice was safe. In addition, administration of probiotics GKS6 and GKK2 significantly delayed the aging process by enhancing antioxidants activity, resulting in lower oxidative damage. Moreover, B. lactis GKK2 showed a significant effect on forelimb strength strengthening and muscle fiber hypergenesis. Both L. paracasei GKS6 and B. lactis GKK2 could act as candidates of functional food for antiaging. B. lactis GKK2 could further be a potential supplementary as an elderly muscle-building diet.

\section{Data Availability}

All the data used to support the findings of this study are included within the article.

\section{Conflicts of Interest}

The authors declare that there are no conflicts of interest.

\section{Authors' Contributions}

S. W. Lin conducted the animal experiments and M. F. Wang helped the data analysis. Tony J. Fang and W. H. Lin supervised the experiments. C. C. Chen and Y. L. Chen gave advice on the rationale of this study. S. W. Lin and Y. S. Tsai contributed to the paper writing. All authors have read and approved the manuscript.

\section{Supplementary Materials}

Figure S1: oxidative stress parameters in SAMP8 mouse brain. The concentrations of thiobarbituric acid reactive substances (a) and 8-hydoxy-2-deoxyguanosine (b) in SAMP8 mouse brain were measured. The values were shown as means \pm SEM with one-way ANOVA $(n=10)$. *Significant difference was presented when $p<0.05$. Control: SAMP8 mice fed with saline; GKS6: SAMP8 mice fed with L. paracasei GKS6; GKK2: SAMP8 mice fed with B. lactis GKK2. Figure S2: Cisd2 expression with probiotic treatments on HEK 293T cell line. A screening test from human embryonic kidney 293T (HEK 293T) cell line revealed by western blot (Fig. S2a) and the Cisd 2 expression was determined as a relative percentage of the control (Fig. S2b). GKS6: L. paracasei GKS6; GKK2: B. lactis GKK2; Cisd2: CDGSH iron-sulfur domain 2; GAPDH: glyceraldehyde-3-phosphate dehydrogenase. Table S1: effect of probiotics on bone parameters in SAMP8 female mice. (Supplementary Materials) 


\section{References}

[1] World Health Organization, World Report on Ageing and Health: Summary (No. WHO/FWC/ALC/15.01), World Health Organization, Geneva, Switzerland, 2015.

[2] M. M. Porter, A. A. Vandervoort, and J. Lexell, "Aging of human muscle: structure, function and adaptability," Scandinavian Journal of Medicine and Science in Sports, vol. 5, no. 3, pp. 129-142, 1995.

[3] D. Jones, V. C. Mody, J. L. Carlson, M. J. Lynn, and P. Sternberg, "Redox analysis of human plasma allows separation of pro-oxidant events of aging from decline in antioxidant defenses," Free Radical Biology and Medicine, vol. 33, no. 9, pp. 1290-1300, 2002.

[4] J. A. Knight, "Free radicals, antioxidants, and the immune system," Annals of Clinical \& Laboratory Science, vol. 30, no. 2, pp. 145-158, 2000.

[5] C. M. Weyand and J. J. Goronzy, "Aging of the immune system. Mechanisms and therapeutic targets," Annals of the American Thoracic Society, vol. 13, pp. S422-S428, 2016.

[6] F. Paneni, C. D. Cañestro, P. Libby, T. F. Lüscher, and G. G. Camici, "The aging cardiovascular system: understanding it at the cellular and clinical levels," Journal of the American College of Cardiology, vol. 69, no. 15, pp. 1952-1967, 2017.

[7] N. S. Fedarko, "The biology of aging and frailty," Clinics in Geriatric Medicine, vol. 27, no. 1, pp. 27-37, 2011.

[8] A. K. Shetty, M. Kodali, R. Upadhya, and L. N. Madhu, "Emerging anti-aging strategies-scientific basis and efficacy," Aging and Disease, vol. 9, no. 6, pp. 1165-1184, 2018.

[9] A. Picca, R. Calvani, M. Bossola et al., "Update on mitochondria and muscle aging: all wrong roads lead to sarcopenia," Biological Chemistry, vol. 399, no. 5, pp. 421-436, 2018.

[10] T. M. Manini and B. C. Clark, "Dynapenia and aging: an update," Journals of Gerontology Series A: Biomedical Sciences and Medical Sciences, vol. 67, no. 1, pp. 28-40, 2012.

[11] D. J. Wilkinson, M. Piasecki, and P. J. Atherton, "The agerelated loss of skeletal muscle mass and function: measurement and physiology of muscle fibre atrophy and muscle fibre loss in humans," Ageing Research Reviews, vol. 47, pp. 123132, 2018.

[12] T. Yazar and H. O. Yazar, "Prevalance of sarcopenia according to decade," Clinical Nutrition ESPEN, vol. 29, pp. 137-141, 2019.

[13] P. Szentesi, L. Csernoch, L. Dux, and A. Keller-Pintér, "Changes in redox signaling in the skeletal muscle with aging," Oxidative Medicine and Cellular Longevity, vol. 2019, Article ID 4617801, 12 pages, 2019.

[14] S. K. Powers, M. Ozdemir, and H. Hyatt, "Redox control of proteolysis during inactivity-induced skeletal muscle atrophy," Antioxidants and Redox Signaling, vol. 33, no. 8, pp. 559-569, 2020.

[15] J. Wang, K.-S. Leung, S. K.-H. Chow, and W.-H. Cheung, "Inflammation and age-associated skeletal muscle deterioration (sarcopaenia)," Journal of Orthopaedic Translation, vol. 10, pp. 94-101, 2017.

[16] S. Xia, X. Zhang, S. Zheng et al., "An update on inflammaging: mechanisms, prevention, and treatment," Journal of Immunology Research, vol. 2016, Article ID 8426874, 12 pages, 2016.

[17] G. Mu, Y. Gao, Y. Tuo et al., "Assessing and comparing antioxidant activities of Lactobacilli strains by using different chemical and cellular antioxidant methods," Journal of Dairy Science, vol. 101, no. 12, pp. 10792-10806, 2018.
[18] N. S. Oh, J. Y. Joung, J. Y. Lee, and Y. Kim, "Probiotic and anti-inflammatory potential of Lactobacillus rhamnosus 4B15 and Lactobacillus gasseri 4M13 isolated from infant feces," PLoS One, vol. 13, no. 2, Article ID e0192021, 2018.

[19] H. Wang, X. Ni, X. Qing et al., "Live probiotic Lactobacillus johnsonii BS15 promotes growth performance and lowers fat deposition by improving lipid metabolism, intestinal development, and gut microflora in broilers," Frontiers in Microbiology, vol. 8, p. 1073, 2017.

[20] Y.-S. Tsai, S.-W. Lin, Y.-L. Chen, and C.-C. Chen, "Effect of probiotics Lactobacillus paracasei GKS6, L. plantarum GKM3, and L. rhamnosus GKLC1 on alleviating alcohol-induced alcoholic liver disease in a mouse model," Nutrition Research and Practice, vol. 14, no. 4, pp. 299-308, 2020.

[21] L.-C. Yang, S.-W. Lin, I.-C. Li et al., "Lactobacillus plantarum GKM3 and Lactobacillus paracasei GKS6 supplementation ameliorates bone loss in ovariectomized mice by promoting osteoblast differentiation and inhibiting osteoclast formation," Nutrients, vol. 12, no. 7, p. 1914, 2020.

[22] Y. H. Hou, S. W. Lin, C. Zhao et al., "Effect of Bifidobacterium lactis GKK2 on OVA-induced asthmatic mice," Hans Journal of Biomedicine, vol. 9, no. 2, 2019.

[23] S. Y. Cho, J. Kim, J. H. Lee et al., "Modulation of gut microbiota and delayed immunosenescence as a result of syringaresinol consumption in middle-aged mice," Scientific Reports, vol. 6, p. 39026, 2016.

[24] D. Brunetti, E. Bottani, A. Segala et al., "Targeting multiple mitochondrial processes by a metabolic modulator prevents sarcopenia and cognitive decline in SAMP8 mice," Frontiers in Pharmacology, vol. 11, p. 1171, 2020.

[25] T. Takeda, M. Hosokawa, S. Takeshita et al., "A new murine model of accelerated senescence," Mechanisms of Ageing and Development, vol. 17, no. 2, pp. 183-194, 1981.

[26] V. L. Tatum, C. Changchit, and C. K. Chow, "Measurement of malondialdehyde by high performance liquid chromatography with fluorescence detection," Lipids, vol. 25, no. 4, pp. 226-229, 1990.

[27] Y.-F. Chen, C.-Y. Wu, R. Kirby, C.-H. Kao, and T.-F. Tsai, “A role for the CISD2 gene in lifespan control and human disease," Annals of the New York Academy of Sciences, vol. 1201, no. 1, pp. 58-64, 2010.

[28] Y.-H. Cheng, F.-H. Lin, C.-Y. Wang et al., "Recovery of oxidative stress-induced damage in Cisd2-deficient cardiomyocytes by sustained release of ferulic acid from injectable hydrogel," Biomaterials, vol. 103, pp. 207-218, 2016.

[29] Y.-C. Teng, J.-Y. Wang, Y.-H. Chi, and T.-F. Tsai, "Exercise and the Cisd 2 prolongevity gene: two promising strategies to delay the aging of skeletal muscle," International Journal of Molecular Sciences, vol. 21, no. 23, p. 9059, 2020.

[30] C. Rouzier, D. Moore, C. Delorme et al., "A novel CISD2 mutation associated with a classical Wolfram syndrome phenotype alters $\mathrm{Ca}^{2+}$ homeostasis and ER-mitochondria interactions," Human Molecular Genetics, vol. 26, no. 9, pp. 1599-1611, 2017.

[31] B. Chen, S. Shen, J. Wu et al., "CISD2 associated with proliferation indicates negative prognosis in patients with hepatocellular carcinoma," International Journal of Clinical and Experimental Pathology, vol. 8, no. 10, p. 13725, 2015.

[32] C.-H. Yeh, Z.-Q. Shen, S.-Y. Hsiung et al., "Cisd2 is essential to delaying cardiac aging and to maintaining heart functions," PLoS Biology, vol. 17, no. 10, Article ID e3000508, 2019.

[33] Y.-L. Huang, Z.-Q. Shen, C.-Y. Wu et al., "Comparative proteomic profiling reveals a role for Cisd2 in skeletal muscle aging," Aging Cell, vol. 17, no. 1, Article ID e12705, 2018. 
[34] E. Gibon, L. Y. Lu, K. Nathan, and S. B. Goodman, "Inflammation, ageing, and bone regeneration," Journal of Orthopaedic Translation, vol. 10, pp. 28-35, 2017.

[35] L. Ginaldi, M. C. Di Benedetto, and M. De Martinis, "Osteoporosis, inflammation and ageing," Immunity and Ageing, vol. 2, no. 1, pp. 1-5, 2005.

[36] Y. Ni, X. Yang, L. Zheng et al., "Lactobacillus and Bifidobacterium improves physiological function and cognitive ability in aged mice by the regulation of gut microbiota," Molecular Nutrition \& Food Research, vol. 63, no. 22, p. 1900603, 2019. 